\title{
What is the Logic behind Treating Some Heart Failure Patients without ACE Inhibitors and Beta-Blockers?
}

Ebraheem Alskaf, Shadia Ahmed, Donna Barnett, Meg Warriner, Andrew Birchall, Victoria Watt and Abdallah Al-Mohammad* Local audit of National Heart Failure Audit data 2012 in Sheffield Teaching Hospitals NHS Foundation Trust, UK

\begin{abstract}
Objectives: To obtain local data on the reasons why hospitalised heart failure patients are not being given a combination of beta-blockers (BB) and Angiotensin Converting Enzyme inhibitors (ACE - I).

Method: A survey was carried out of the heart failure patients discharged in the year 2012 from Sheffield Teaching Hospitals and reported to the National Heart Failure Audit who was not on ACE-I or BB. The main measures were the reasons for not giving those agents, and the use of alternative medications.

Results: The total number of our heart failure patients who were reported to the National Heart Failure Audit in 2012, and who were not on ACE-I or BB was 96 patients. Of these, 38 patients $(40 \%)$ had heart failure with preserved ejection fraction (HFPEF), and 58 patients $(60 \%)$ had left ventricular systolic dysfunction (LVSD).

Of the 58 patients with HF-LVSD, 25 patients did not have contraindications to either ACE-I or BB. However, 2 of them were on end of life care pathway (EOLCP) and thus were appropriately managed, this leaves 23/98 $(23.5 \%)$ of overall patients managed inappropriately. Contraindications to or adverse effects from ACE-I or BB were encountered in $35 / 58$ and $15 / 58$ of the patients, respectively.
\end{abstract}

Conclusion: HFPEF is the main reason for not using BB and ACE-I in heart failure patients, followed by contraindications to these agents. ACE inhibitors had higher rate of adverse effects than beta blockers.

Keywords: ACE inhibitors; Beta-blockers; Heart failure

\section{Introduction}

The morbidity and mortality rates of patients with heart failure have progressively fallen through the cumulative effects of several classes of agents including angiotensin converting enzyme inhibitors (ACE-I), beta-blockers $(\mathrm{BB})$, aldosterone antagonists (mineralocorticoid receptor antagonists, MRA), combined arterial and venous dilators (combined hydralazine and nitrates, $\mathrm{Hyd}+\mathrm{N}$ ) and angiotensin receptor blockers (ARB) [1]. These advances have been achieved in the treatment of heart failure associated with reduced left ventricular ejection fraction or HF with LVSD, which comprises almost $50 \%$ of the heart failure patient population in the community and around $65-70 \%$ of hospitalised heart failure patients. However, there is no evidence to support their use in HFPEF patients [2-4]. The evidence supports the use of both ACE inhibitors and beta-blockers licensed for heart failure to all patients with heart failure due to left ventricular systolic dysfunction as a first line treatment [5-10].

The National Heart Failure Audit published in December 2010 showed that the prognosis of patients hospitalised with heart failure remains poor and the treatment is suboptimal, but could improve with specialist services [11]. The audit showed particularly that betablockers were much less used in heart failure patients than ACE inhibitors. Although the results from our institution were better than the average reported nationally in the last three years, there were a stable percentage of patients reported by our institution who did not receive these two agents in both 2011 and 2012. Thus, we posed the question as to whether there were good reasons for not using ACE inhibitors and beta-blockers in some of the patients with heart failure, to explain the plateau that we seem to have reached.

We audited whether those who have heart failure and were not discharged on these approved first line medications had good justification for not being offered such therapy?

\section{Method}

A secure data-base called Infoflex is adopted by heart failure service in Sheffield Teaching Hospitals NHS Foundation Trust was our source of information. A retrospective study was performed on the cohort group of heart failure patients who were discharged in the year 2012 from our institution with heart failure and were reported to the National Heart Failure Audit, but were not on ACE inhibitors and beta-blockers. All age groups were included in the audit. The gender of the patients had no impact on the choice of medication for heart failure patients.

A special proforma was used to collect the data (Figure 1). The focus was on 4 fields in Infoflex data base, those were: patient details, discharge medications and summary, transthoracic Echocardiography reports and heart failure multidisciplinary team (MDT) letters.

For each of the two drugs, the patients who did not receive the drug were identified from the database and from the log of the patients reported to the National Heart Failure Audit. The purpose of the study was to assess which patients did not have left ventricular systolic dysfunction and did not qualify for the therapy (group A), then to assess the patients who did have LVSD (group B).

In group B we studied the reasons for not giving first line agents

*Corresponding author: Abdallah Al-Mohammad, Heart Failure Services Cardiology Department, Northern General Hospital, Harries Road, Sheffield, South Yorkshire, S5 7AU, UK, E-mail: a.al.mohammad.87@googlemail.com

Received June 24, 2014; Accepted July 29, 2014; Published August 05, 2014

Citation: Alskaf E, Ahmed S, Barnett D, Warriner M, Birchall A, et al. (2014) What is the Logic behind Treating Some Heart Failure Patients without ACE Inhibitors and Beta-Blockers? J Pharmacogenomics Pharmacoproteomics 5: 137. doi:10.4172/2153-0645.1000137

Copyright: (C) 2014 Alskaf E, et al. This is an open-access article distributed under the terms of the Creative Commons Attribution License, which permits unrestricted use, distribution, and reproduction in any medium, provided the original author and source are credited. 


\section{HF Discharged not on ACEI/BB Audit Data Collection Proforma}

1. Hospital number

\section{Age}

3. Date of discharge
No O

4. LVSD
If No, then the lack of ACEI/BB is appropriate and no further questions are needed

If Yes, then go to question 5

5. On ACE-i on discharge

6. If no, is it contraindicated?

7. If no, on alternate first line Mx?

8. On $\mathrm{BB}$ on discharge

9. If no, is it contraindicated?

10. Alternate Mx used

12. Comments

\begin{tabular}{|c|c|c|}
\hline Yes & $\mathrm{O}$ & No \\
\hline Yes & $\mathrm{O}$ & No \\
\hline Yes & $\mathrm{O}$ & No \\
\hline Yes & $\mathrm{O}$ & No \\
\hline Yes & $\mathrm{O}$ & No \\
\hline
\end{tabular}

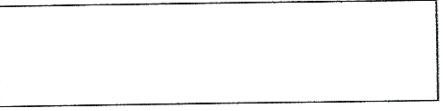

Figure 1: Sample of data collection pro-forma.

for heart failure. The data were collected from discharge summaries and MDT letters. Then we looked at the use of alternatives to first line medications. We calculated the percentage of patients on each drug group, then the percentages of subgroups who had true contraindications, and those who did not and were considered as managed inappropriately.

We looked at group B patients and compared two subgroups, patients not on ACE inhibitors and patients not on beta-blockers. We 


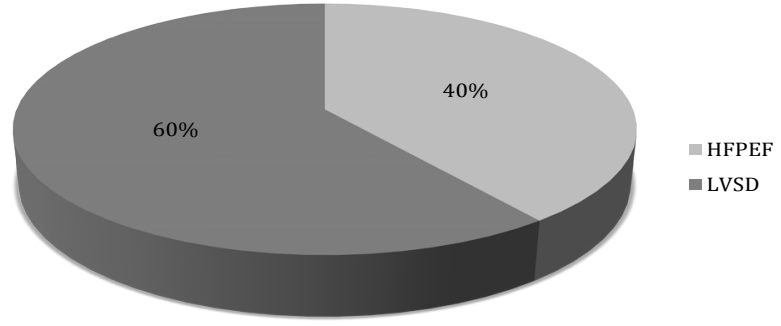

Figure 2: The percentages of LVSD and HFPEF patients who were discharged without ACE-I and BB.

\begin{tabular}{|c|c|c|c|c|c|c|}
\hline \multicolumn{7}{|c|}{ Contraindications } \\
\hline ACE-i & $\begin{array}{c}\text { Kidney } \\
\text { disease }\end{array}$ & Intolerance & Hypotension & $\begin{array}{c}\text { Hyperka- } \\
\text { laemia }\end{array}$ & $\begin{array}{c}\text { Severe Aortic } \\
\text { stenosis }\end{array}$ & allergy \\
\hline $\begin{array}{c}\text { Beta- } \\
\text { blockers }\end{array}$ & Asthma & $\begin{array}{c}\text { COPD with } \\
\text { wheezing }\end{array}$ & Bradycardia & $\begin{array}{c}\text { Hypoten- } \\
\text { sion }\end{array}$ & $\begin{array}{c}\text { Complete heart } \\
\text { block }\end{array}$ & $\begin{array}{c}2^{\text {nd }} \text { degree } \\
\text { heart block }\end{array}$ \\
\hline
\end{tabular}

Table 1: Contraindications of ACE-I and BB found in Group B patients.

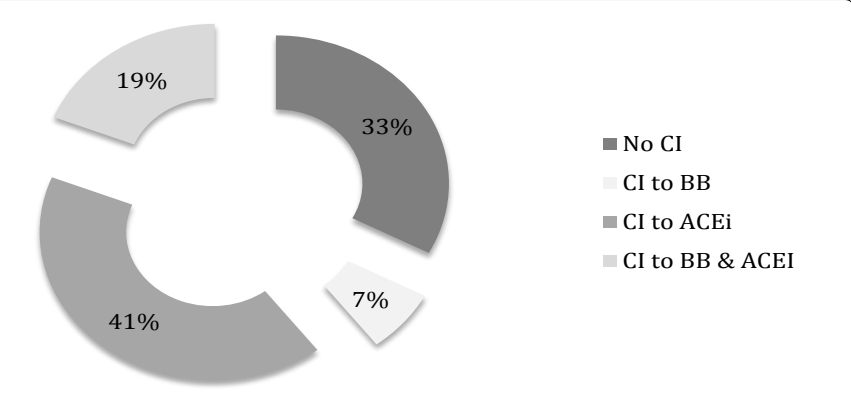

Figure 3: The distribution of contraindications amongst patients in Group B.

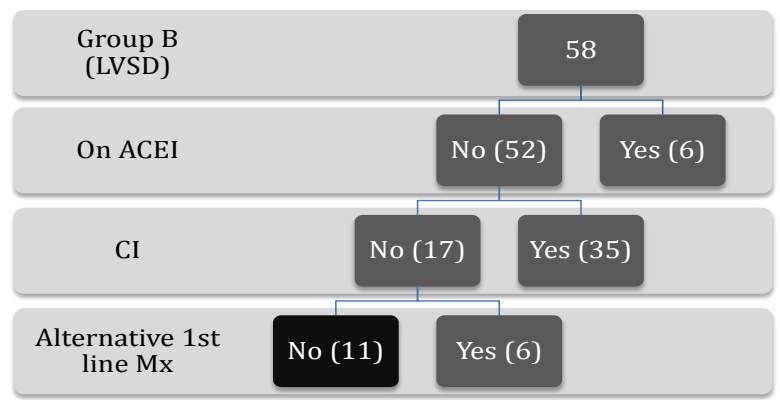

Figure 4: Management of Group B patients who were discharged without ACE-I explained.

ascertained the percentage of those with adverse effects, the use of alternative first line medications to ACE-I [12-15], the use of second line medications [16-18] and the use of single first line agents (either ACE-I or BB).

This is an observational audit since no intervention was undertaken, it was not necessary to seek ethical approval, although approval from the audit department was granted. All data collection forms were anonymised.

\section{Results}

We identified 96 patients from the heart failure data-base who were reported to the National Heart Failure Audit and discharged from
Sheffield Teaching Hospital without being on the combination of ACE inhibitors and beta blockers in 2012 .

Our standards were obtained from National Institute of Health and Care Excellence (NICE) guidelines No 108 August 2010, summarised in the following statements [1]:

- Offer both angiotensin-converting enzyme (ACE) inhibitors and beta-blockers licensed for heart failure to all patients with heart failure due to left ventricular systolic dysfunction. Use clinical judgment when deciding which drug to start first $[9,10]$.

- Offer beta-blockers licensed for heart failure to all patients with heart failure due to left ventricular systolic dysfunction, including: older adults and patients with peripheral vascular disease, erectile dysfunction, diabetes mellitus, interstitial pulmonary disease and chronic obstructive pulmonary disease (COPD) without reversibility [5-8].

- The evidence was inadequate to support the use of ACE-I in HFPEF $[2,3]$.

- There are no studies that specifically looked at the use of betablockers in the treatment of HFPEF [4].

We identified group A patients who had HFPEF from the cohort group, the total number was 38 patients $(38 / 96=40 \%)$, then group B patients who had LVSD and the number was $58(58 / 96=60 \%)$ (Figure 2).

As group B patients had to have first line therapy for heart failure due to LVSD, we looked for justification for the failure to achieve the standard was justifiable. The main factors were contraindications to first line agents, as summarized in Table 1.

Within group B: The patients who had contra-indications to both agents was $11 / 58(19 \%)$, the patients who had contra-indications to ACE inhibitors only were $24 / 58$ (41\%) and the patients who had contraindications to beta-blockers only were $4 / 58(7 \%)$. Thus, although these patients were not receiving first line therapy, they are considered appropriately managed because they had genuine contra-indications to the first line therapy.

Within group $\mathrm{B}$, the number of patients who did not have contraindications to either of the two first line agents (ACE-I and BB) was 19/58 (33\%) (Figure 3).

We looked at the use of alternative first line agents in patients who did not receive ACE inhibitors in group B (Figure 4).

Although 6 patients (of the 58 patients in group B) did receive alternative agents, these patients did not have contraindications to the main agents, thus they were considered as managed inappropriately. This would leave 11/58 patients without ACE-I or alternative 1st line medications.

On the other hand, in (Figure 5) 35/58 patients were qualified to be on beta-blockers but were not given them. Of these 35 patients, there were 27 patients who did receive ACE inhibitors. Thus they were not mismanaged. This leaves $8 / 58$ without any 1 st line agents.

Therefore, within group B patients the total number of patients who qualified for BB and ACE-I but didn't receive any was $6+11+8=25 / 58$ (43\%).

The discharge summaries and heart failure MDT letters were reviewed, and we found that there were 2 patients who were commenced on end of life care pathway (EOLCP) as they had very poor prognosis 


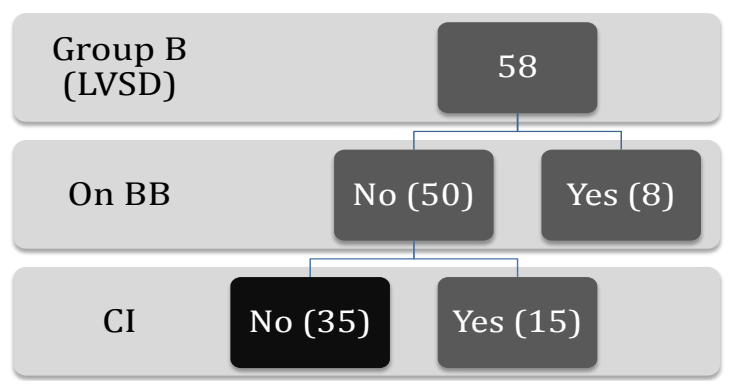

Figure 5: Management of Group B patients who were discharged without BB explained.
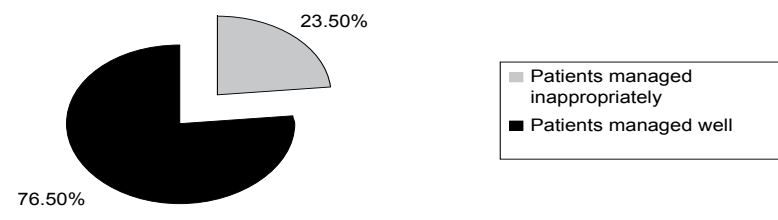

Figure 6: The overall percentage of patients who were managed well or inappropriately.

\begin{tabular}{|c|c|c|}
\hline & Not on ACE-i & Not on BB \\
\hline Adverse effects & $32 / 52(61.5 \%)$ & $15 / 50(30 \%)$ \\
\hline Use of alt $\mathbf{1}^{\text {st }}$ line Mx to ACE-I & $12 / 52(23 \%)$ & $9 / 50(18 \%)$ \\
\hline Use of $\mathbf{2}^{\text {nd }}$ line Mx & $15 / 52(28.8 \%)$ & $15 / 50(30 \%)$ \\
\hline Use of single1 ${ }^{\text {st }}$ line Mx & $7 / 52(13.4 \%)$ & $6 / 50(12 \%)$ \\
\hline
\end{tabular}

Table 2: Comparing side effects and the use of alternative agents between patients who did not receive ACE-I and the ones who did not receive BB.

and were appropriately not given any of these medications. Therefore, $23 / 58$ (39.6\%) of the patients were managed inappropriately, and the percentage from the total cohort group of 98 patients would be 23/98 (23.5\%) (Figure 6).

Finally, we compared two subgroups in group B, patients not on ACE-I or not on $\mathrm{BB}$, regarding side effects and the use of alternative medications (Table 2).

In the analysis of group $\mathrm{B}$, the striking finding is that the rate of side effects to ACE inhibitors was twice as high as the rate in patients on beta-blockers.

The use of alternative first line medications to ACE-I was higher in patients who did not have ACE inhibitors than the ones who did not have beta blockers.

Finally, the use of second line medications or continuing use of a single first line agent remained fairly similar in both groups (Figure 7).

\section{Discussion}

This was a local audit reviewing the reasons why first line therapeutic agents were not given to patients hospitalised with heart failure. Although our centre is achieving rates higher than the national average of applying evidence based therapy in heart failure, there were strong reasons for not using these agents in some of the patients at the time of discharge. When the failure to prescribe a first line agent to a patient with heart failure is justified by the presence of absolute contraindication then the management is considered appropriate.

We have had several limitations; one was the small size of the cohort. This is something we do not need to apologise for as the normal good practice should be associated with only a small group of patients in whom the treatment deviates from the guidelines.

We noted discrepancy between the discharge medication list and the advice by the heart failure specialist proposed in the heart failure MDT. We have not specifically analyzed whether the clinicians' decision to deviate from the HF MDT advice was clinically justified or not. We noted several patients had received HF MDT advice not to commence on ACE inhibitors or beta-blockers. These decisions are due to contraindication to these agents.

One of the patients died before having a trans-thoracic echocardiogram that was scheduled to be done as an out-patient and thus it was not possible to assign the patient to either group A or B. This was, however, an anomaly as the echocardiogram should have been done as an inpatient, or failing that it would have safer to have commenced the patient on ACE-I and BB and these agents could be withdrawn if the echocardiogram did not show LVSD.

We have also noted in the review that patients were on one of the two vasodilators hydralazine or nitrates, rather than being on the combination of these agents. There is no evidence to support the use of one of the two agents as a single therapy in patient with heart failure LVSD, therefore these patients were deemed as not being managed well, unless hydralazine was being given to control hypertension and nitrates were being given to treat angina as co-morbidities $[1,16]$.

The main reasons for not being given the combination of ACE inhibitors and beta-blockers in patients hospitalised with heart failure were having HFPEF [2-4] or the presence of contraindications to those agents. . Our specialist heart failure team reviews these patients and reconsiders the contraindications regularly. The agents are considered for re-introduction whenever possible.

Although adverse effects were much more common in the ACE inhibitors group, some patients in this group were started on alternative first line medications $[19,20]$.

The use of beta-blockers was suboptimal although their side effects were much less that ACE-I. Despite the evidence supporting the use of beta-blockers licensed for use in heart failure due to LVSD, there are some physicians who hesitate to prescribe them.

We have also found that the use of alternative first and second line therapy still suboptimal.

We propose that the data collection by the National Heart Failure Audit should include comments about the reasons why certain agents were not being given to patients with heart failure. This will improve the

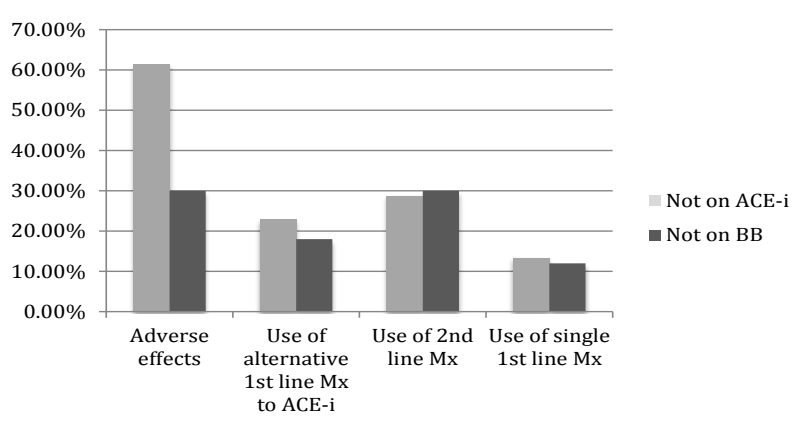

Figure 7: A diagram of the final subgroups analysis in group B. 
Citation: Alskaf E, Ahmed S, Barnett D, Warriner M, Birchall A, et al. (2014) What is the Logic behind Treating Some Heart Failure Patients without ACE Inhibitors and Beta-Blockers? J Pharmacogenomics Pharmacoproteomics 5: 137. doi:10.4172/2153-0645.1000137

assessment of the performance of individual centres and may help give a more informed picture of the care offered to heart failure patients. Such detailed reporting of the results will enable the clinicians to clarify whether not prescribing certain medication is justified or not. This will also make the comparison between centres more reliable and would allow centres to have a more accurate assessment of the extent of underachievement of the quality standards of caring for heart failure patients.

\section{Acknowledgement} Yates.

The authors acknowledge the help received from the IT manager Ms Louisa

\section{Conflict of Interests}

Contributors Each of the authors helped in collection of the data. EA and AAM planned the audit, analysed the data and wrote the manuscript.

\section{References}

1. National Institute for Health and Clinical Excellence (2010) Chronic hear Failure: National Clinical Guideline (CG108). Royal College of Physicians, London.

2. Zi M, Carmichael N, Lye M (2003) The effect of quinapril on functional status of elderly patients with diastolic heart failure. Cardiovasc Drugs Ther 17: 133-139.

3. Cleland JG, Tendera M, Adamus J, Freemantle N, Polonski L, et al. (2006) The perindopril in elderly people with chronic heart failure (PEP-CHF) study. Eur Heart J 27: 2338-2345.

4. van Veldhuisen DJ, Cohen-Solal A, Böhm M, Anker SD, Babalis D, et al. (2009) Beta-blockade with nebivolol in elderly heart failure patients with impaired and preserved left ventricular ejection fraction: Data from SENIORS (Study of Effects of Nebivolol Intervention on Outcomes and Rehospitalization in Seniors With Heart Failure). J Am Coll Cardiol 53: 2150-2158.

5. Colucci WS, Kolias TJ, Adams KF, Armstrong WF, Ghali JK, et al. (2007) Metoprolol reverses left ventricular remodeling in patients with asymptomatic systolic dysfunction: the Reversal of Ventricular Remodeling with Toprol-XL (REVERT) trial. Ciculation 116: 49-56.

6. Exner DV, Dries DL, Waclawiw MA, Shelton B, Domanski MJ (1999) Betaadrenergic blocking agent use and mortality in patients with asymptomatic and symptomatic left ventricular systolic dysfunction: a post hoc analysis of the Studies of Left Ventricular Dysfunction. J Am Coll Cardiol 33: 916-923.

7. Dekleva M, Düngen HD, Gelbrich G, Incrot S, Suzic Lazic J, et al. (2012) Beta blockers therapy is associated with improved left ventricular systolic function and sustained exercise capacity in elderly patients with heart failure. CIBISELD sub-study. Aging Clin Exp Res 24: 675-681.

8. Cleland JGF, Pennell DJ, Ray SG, Coats AJ, Macfarlane PW, et al. (2003) Myocardial viability as a determinant of the ejection fraction response to carvedilol in patients with heart failure (CHRISTMAS trial): randomized controlled trial. Lancet 362: 14-21.
9. Garg R, Yosuf S (1995) Overview of randomized trials of angiotensin-converting enzyme inhibitors on mortality and morbidity in patients with heart failure. Collaborative Group on ACE Inhibitors Trials. JAMA 273: 1450-1456.

10. Flather MD, Yusuf S, Køber L, Pfeffer M, Hall A, et al. (2000) Long-term ACE inhibitors therapy in patients with heart failure or left-ventricular dysfunction: a systematic overview of data from individual patients. ACE-Inhibitors Myocardial Infarction Collaborative Group. Lancet 355: 1575-1581.

11. Cleland JGF, McDonagh T, Rigby AS, Yassin A, Whittaker T, et al. (2011) The national heart failure audit for England and Wales 2008-2009. Heart 97: 876886

12. Young JB, Dunlap ME, Pfeffer MA, Probstfield JL, Cohen-Solal A, et al. (2004) Mortality and morbidity reduction with Candesartan in patients with chronic heart failure and left ventricular systolic dysfunction: results of the CHARM lowleft ventricular ejection fraction trials. Circulation 110: 2618-2626.

13. Dickstein K, Kjekshus J, OPTIMAAL Steering Committee of the OPTIMAAL Study Group (2002) Effects of losartan and captopril on mortality and morbidity in high-risk patients after acute myocardial infarction: The OPTIMAAL randomized trial. Lancet 360: 752-760.

14. Cohn JN, Tognoni G, Valsartan Heart Failure Trial Investigators (2001) A randomized trial of the angiotensin-receptor blocker valsartan in chronic heart failure. N Engl J Med 345: 1667-1675.

15. Maggioni AP, Anand I, Gottlieb SO, Latini R, Tognoni G, et al. (2002) Effects of valsartan on morbidity and mortality in patients with heart failure no receiving angiotensin-converting enzyme inhibitors. J Am Coll Cardiol 40: 1414-1421.

16. Gogia H, Mehra A, Parikh S, Raman M, Ajit-Uppal J, et al. (1995) Prevention of tolerance to hemodynamic effects of nitrates with concomitant use of hydralazine in patients with chronic heart failure. J Am Coll Cardiol 26: 15751580.

17. Pitt B1, Zannad F, Remme WJ, Cody R, Castaigne A, et al. (1999) The effect of spironolactone on morbidity and mortality in patients with severe heart failure. Randomized Aldactone Evaluation Study Investigators. N Engl J Med 341: 709717.

18. Pitt B, Remme W, Zannad F, Neaton J, Martinez F, et al. (2003) Eplerenone, a selective aldosterone blocker, in patients with left ventricular dysfunction after myocardial infarction. N Engl J Med 348: 1309-1321.

19. Sica DA (2004) ACE inhibitors intolerance and lessons learned from the candesartan in heart failure: assessment of reduction in mortality and morbidity (CHARM) trials. Congest Heart Fail 10: 160-164.

20. Granger CB, McMurray JJ, Yusuf S, Held P, Michelson EL, et al. (2004) Effects of candesartan in patients with chronic heart failure and reduced left-ventricular systolic function intolerant to antiotensin-converting-enzyme inhibitors: the CHARM-alternative trial. Lancet 362: 772-776. 